\title{
Activity of Nitric Oxide Is Dependent On, But Is Partially Required for Function of, Salicylic Acid in the Signaling Pathway in Tobacco Systemic Acquired Resistance
}

\author{
Fengming Song and Robert M. Goodman \\ Department of Plant Pathology, 1630 Linden Drive, University of Wisconsin, Madison 53706 U.S.A. \\ Submitted 13 July 2001; Accepted 5 September 2001.
}

\begin{abstract}
When tobacco plants were treated by injection with nitric oxide (NO)-releasing compounds, the sizes of lesions caused by Tobacco mosaic virus (TMV) on the treated leaves and on upper nontreated leaves were significantly reduced. The reduction in TMV lesion size was caused by NO released from the NO-releasing compounds; the byproduct formed after release of NO from the NO-releasing compound NOC-18, diethylenetriamine, did not itself alter lesion size. Treatment of tobacco plants with inhibitors of nitric oxide synthase or an NO scavenger attenuated but did not abolish the systemic acquired resistance (SAR) induced by salicylic acid (SA). In NahG transgenic tobacco plants, NO had no effect on lesion size following TMV infection. These results are consistent with the hypothesis that NO plays an important role in SAR induction in tobacco and that NO is required for the full function of $S A$ as an SAR inducer. The activity of $\mathrm{NO}$ is fully dependent on the function of SA in the SAR signaling pathway in tobacco.
\end{abstract}

Additional keywords: defense response.

The physiological functions of nitric oxide (NO) have been extensively documented in mammalian systems and NO has been established to be an important signal molecule in the immune, vascular, and nervous systems of animals (Wink and Mitchell 1998). Although less is known about NO in plant systems, accumulating evidence shows that NO may be involved in various aspects of plant growth, development, and response to environmental stress such as photomorphogenesis, leaf expansion, root growth, shoot formation, and senescence (Beligni and Lamattina 2000; Gouvea et al. 1997; Kurosaki et al. 2000; Leshem et al. 1998; Leshem and Pinchasov 2000). NO may also play roles in protecting plants from UV light and herbicide damage (Beligni and Lamattina 1999a, 1999b; Mackerness et al. 2001).

Corresponding author: R. M. Goodman; Telephone: +1-608-262-9162; Fax: +1-608-262-8643; E-mail: rgoodman @ facstaff.wisc.edu

Current address of Fengming Song: Department of Plant Protection, College of Agriculture and Biotechnology, Zhejiang UniversityHuajiachi Campus, Hangzhou, Zhejiang 310029, P. R. China; E-mail: fmsong@zju.edu.cn
Nitric oxide synthase (NOS) is the major enzyme catalyzing biosynthesis of NO in mammals. The mechanisms for NO production in plants are unknown, but NOS-like enzyme activity has been detected in a variety of plant species (Barroso et al. 1999; Cueto et al. 1996; Ninnemann et al. 1996; Ribeirio et al. 1999; Sen and Cheema 1995), suggesting an NOS-catalyzed NO production mechanism may exist in plants. NO is also produced enzymatically from $\mathrm{NO}_{2}^{-}$in plants by $\mathrm{NAD}(\mathrm{P}) \mathrm{H}-$ dependent nitrate reductase (Yamasaki and Sakihama 2000).

Recently, NO has been demonstrated to be a signal in plant defense responses (Bolwell 1999; Durner and Klessig 1999; Hausladen and Stamler 1998; Klessig et al. 2000; Wendehenne et al. 2001). NO burst has been observed in Arabidopsis, tobacco and soybean plant tissues, suspension-cultured cells treated with avirulent bacterial pathogens or elicitors, and apoptosis of plant cells (Clarke et al. 2000; Delledonne et al. 1998; Foissner et al. 2000; Klepper 1991; Pedroso et al. 2000). Also, NO may be involved in the initiation of programmed cell death, activation of pathogenesis-related (PR) gene expression, and production of phytoalexins (Clarke et al. 2000; Delledonne et al. 1998; Durner et al. 1998; Huang and Knopp 1998; Noritake et al. 1996). In tobacco, NO was found to activate a MAP kinase cascade and to inhibit catalase, ascorbate peroxidase, and aconitase (Clark et al. 2000; Kumar and Klessig 2000; Navarre et al. 2000). Treatment of tobacco leaves with NOS, cofactors, and substrates was found to increase the endogenous salicylic acid (SA) levels and induce PR-1 protein accumulation; but NO-induced PR gene expression was suppressed in NahG transgenic tobacco plants (Durner et al. 1998).

We phenotypically tested the role of NO and its relationship to SA in the signaling pathway leading to activation of systemic acquired resistance (SAR) in tobacco. Our results indicate that NO plays an important role in SAR induction in tobacco and that NO is partially required for the full function of SA. The activity of NO is fully dependent on the function of $\mathrm{SA}$ in the signaling pathway leading to the development of tobacco SAR.

Four-week-old tobacco plants (Nicotiana tabacum cv. Xanthi nc) were grown in a growth chamber under $14 \mathrm{~h}$ of light $\left(27^{\circ} \mathrm{C}\right)$ and $10 \mathrm{~h}$ of dark $\left(22^{\circ} \mathrm{C}\right)$. NO-releasing compounds, 2,2(hydroxynitrosohydrazino) bis-ethanamine (NOC-18, $1.0 \mathrm{mM}$ ), 
( \pm ) $S$-nitroso- $N$-acetylpenicillamine (SNAP, $0.5 \mathrm{mM}$ ), or $S$ nitrosoglutathione (GSNO, $1.0 \mathrm{mM}$ ) (Calbiochem, San Diego,

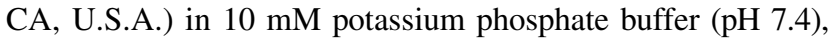
as well as the buffer or water as control, were injected, using a 1-ml syringe without a needle, into extracellular spaces at four locations on a single leaf of each plant. Tobacco mosaic virus (TMV; strain U5) inoculation was performed 5 days after injection with the compounds by gently rubbing the treated and upper nontreated leaves with $200 \mu \mathrm{l}$ of the viral suspension $(12 \mu \mathrm{g} / \mathrm{ml})$ containing Carborundum. A minimum of 20 lesions per leaf were randomly chosen and measured 7 days after inoculation. All experiments were repeated twice, and the results reported represent the means \pm standard deviations from three independent experiments.

We first tested whether NO-releasing compounds could induce disease resistance against TMV in tobacco. As shown in Figure 1, when the tobacco plants were treated by injection with NO-releasing compounds (NO-treated plants), an enhanced resistance against TMV infection was observed both in the treated and nontreated upper leaves. There was no significant difference in TMV lesion size between water- and buffertreated controls. Compared with lesions in the water-treated control, TMV lesion sizes on the leaves of NO-treated plants were reduced markedly, reductions of 53,46 , and $44 \%$ in leaves injected with the NO-releasing compounds and 51, 44,

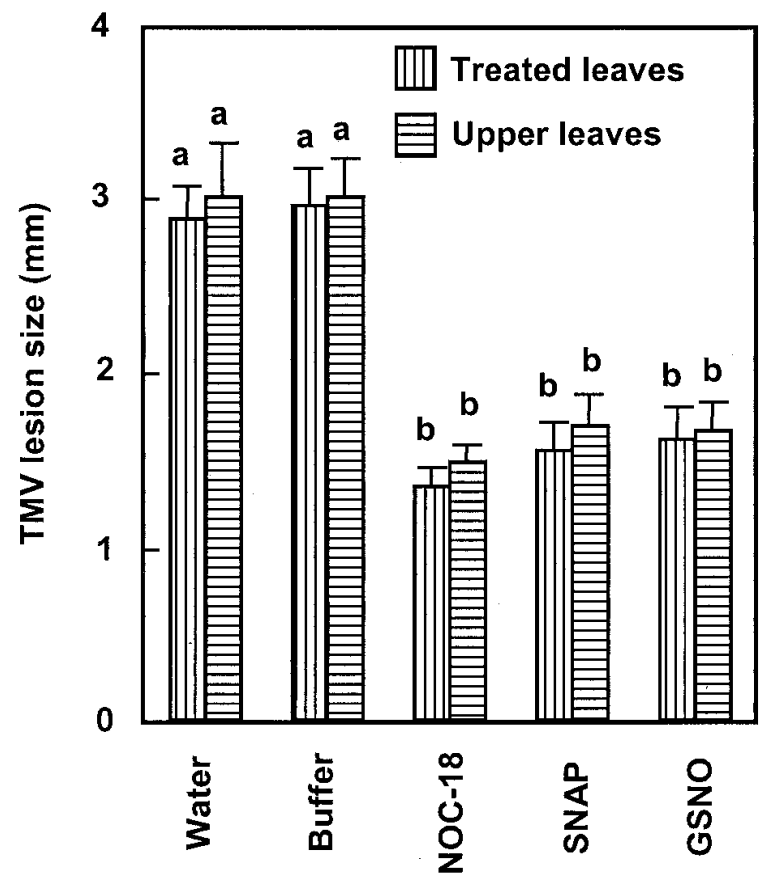

Treatments

Fig. 1. Nitric oxide-releasing compounds induce resistance in tobacco against Tobacco mosaic virus (TMV) infection. Four-week-old tobacco (cv. Xanthi nc) plants were injected with NOC-18 $(1.0 \mathrm{mM}), S$-nitroso$\mathrm{N}$-acetylpenicillamine $(0.5 \mathrm{mM})$, or $S$-nitrosoglutathione $(1.0 \mathrm{mM})$ in 10 $\mathrm{mM}$ potassium phosphate buffer ( $\mathrm{pH}$ 7.4), as well as the buffer or water, at four locations on a single leaf. The treated and upper nontreated leaves were challenged by inoculation with TMV 5 days after treatment. Lesion size was measured 7 days after inoculation. The data presented are the means \pm standard deviations from three independent experiments. The bars with the same letter are not significantly different at $P \leq 0.05$. and $45 \%$ in upper nontreated leaves in NOC-18-, SNAP-, and GSNO-treated plants, respectively. This result suggested that the NO-releasing compounds could induce systemic resistance against TMV infection in tobacco. In a time-course study, the NOC-18-injected plants were challenged by inoculation with TMV at different intervals after injection. The TMV lesion sizes in the plants challenged at intervals of 1,3 , and 5 days after injection were reduced by 48,45 , and $51 \%$ compared with those in the water-treated control plants (Fig. 2), indicating that the NO-mediated disease resistance can be maintained at a relatively high level for a relatively long period. However, the levels of NO-mediated disease resistance in both injected and noninjected leaves were lower than the levels in leaves treated with SA (Fig. 3).

Another experiment was conducted to determine whether reduction of TMV lesion size in NO-treated plants was a consequence of action of NO released from the compounds. A byproduct, diethylenetriamine (DETA), is formed after the release of NO from NOC-18. We therefore compared the abilities of NOC-18 (1.0 mM) and DETA $(1.0 \mathrm{mM})$ (Aldrich, Milwaukee, WI, U.S.A.) to induce resistance in tobacco. As shown in Figure 2, TMV lesion size in DETA-injected plants was similar to that in the water- and buffer-treated controls, whereas lesion size in NOC-18-injected plants was significantly reduced. This result indicates that reduction of TMV le-

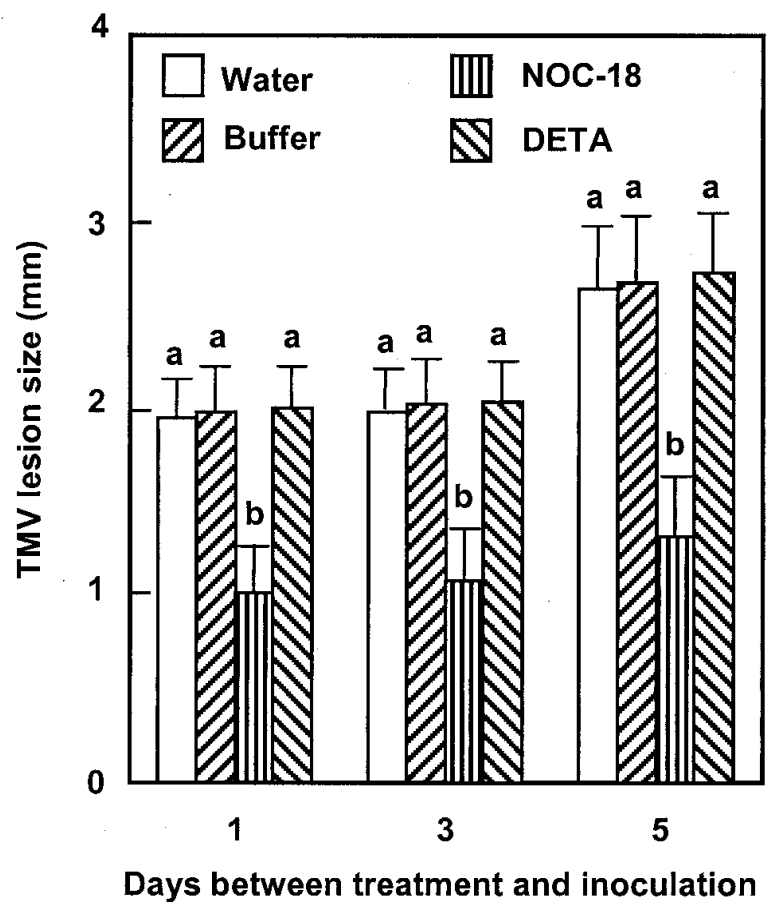

Fig. 2. Nitric oxide (NO) is responsible for the enhanced resistance to Tobacco mosaic virus (TMV) infection induced by NO-releasing compounds in tobacco. Four-week-old tobacco (cv. Xanthi nc) plants were injected with NOC-18 $(1.0 \mathrm{mM})$ or diethylenetriamine $(1.0 \mathrm{mM})$ in 10 $\mathrm{mM}$ potassium phosphate buffer $(\mathrm{pH} \mathrm{7.4)}$, as well as with the buffer or water, at four locations on a single leaf. The treated leaves were challenged by inoculation with TMV at intervals of 1,3 , and 5 days after treatment. Lesion size was measured 7 days after inoculation. The data presented are the means \pm standard deviations from three independent experiments. The bars with the same letter are not significantly different at $P \leq 0.05$. 
sion size in NO-releasing compound-treated plants was caused by action of NO and not DETA.

SA is an effective chemical SAR-inducer in plants, including tobacco (Ward et al. 1991), and has been demonstrated to be one of the most important signals leading to the activation of defense responses (Dong 1998, 2000; Klessig et al. 2000). Therefore, we tested whether endogenously produced NO is required for the development of SAR induced by SA in tobacco. Tobacco plants were treated by injection with mixtures of SA (1.0 mM) (Sigma, St. Louis) and NOS inhibitors $N^{\mathrm{G}}$ monomethyl-L-arginine (L-NMMA, $0.3 \mathrm{mM}$ ) or diphenyleneiodonium chloride (DPI, $0.3 \mathrm{mM}$ ), or with NO scavenger 2phenyl-4,4,5,5-tetramethylimidazoline-1-oxyl-3-oxide (PTIO, $1.0 \mathrm{mM}$ ) (Calbiochem, San Diego, CA, U.S.A.) in potassium phosphate buffer, or with SA $(1.0 \mathrm{mM})$, or with water. In our experiments, injection of the tobacco plants with SA induced a typical SAR response (Ross 1961), resulting in a reduction of TMV lesion size by approximately $70 \%$ compared with that in water-treated controls. When SA was coinjected with the NOS inhibitors L-NMMA or DPI, or with the NO scavenger PTIO,

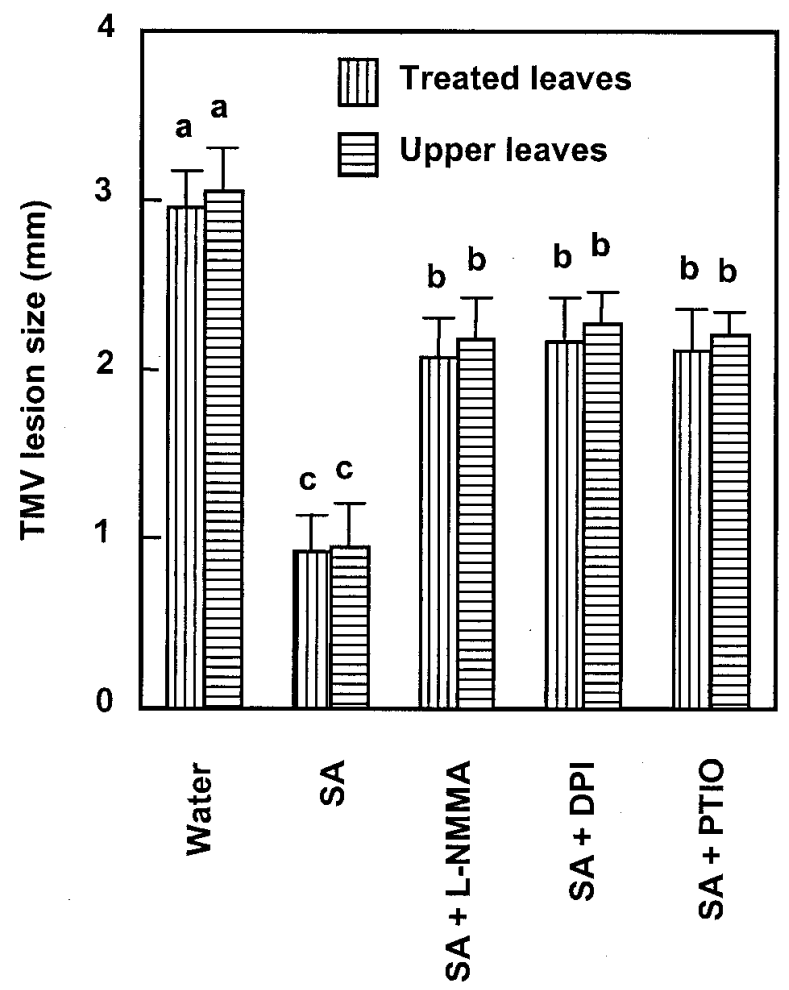

Treatments

Fig. 3. Nitric oxide (NO) is required for the development of systemic acquired resistance (SAR) induced by salicylic acid (SA) in tobacco against Tobacco mosaic virus (TMV) infection. Four-week-old tobacco (cv. Xanthi nc) plants were injected with SA $(1.0 \mathrm{mM})$, mixtures of SA $(1.0 \mathrm{mM})$ and the inhibitors of nitric oxide synthase (L-NMMA, 0.3 $\mathrm{mM}$; DPI, $0.3 \mathrm{mM}$ ), or the NO scavenger 2-phenyl-4,4,5,5-tetramethylimidazoline-1-oxyl-3-oxide $(1.0 \mathrm{mM})$ in $10 \mathrm{mM}$ potassium phosphate buffer ( $\mathrm{pH} 7.4$ ), as well as the buffer or water, at four locations on a single leaf. The treated and upper nontreated leaves were challenged by inoculation with TMV 5 days after treatment. Lesion size was measured 7 days after inoculation. The data presented are the means \pm standard deviations from three independent experiments. The bars with the same letter are not significantly different at $P \leq 0.05$. the SA-induced SAR was attenuated significantly (Fig. 3). In comparison with lesions in SA-injected plants, TMV lesion size was markedly enlarged, an increase of approximately 126 to $136 \%$, both in treated and upper nontreated leaves of the plants injected with mixtures of SA and the inhibitors or the scavenger. The lesions were, however, still smaller (by approximately 25 to $30 \%$ ) than those in the water-treated control. This result shows that NO is required for the development of SAR induced by SA in tobacco.

Transgenic NahG tobacco plants are unable to accumulate SA and develop SAR upon treatment with exogenous SA (Gaffney et al. 1993). To test the interaction of NO-mediated disease resistance and SA accumulation, 4-week-old NahG transgenic tobacco (cv. Xanthi nc) plants were treated by injection with the NO-releasing compound NOC-18 (1.0 mM) in potassium phosphate buffer, or with the buffer, or with water and then inoculated with TMV. TMV lesion size in the NOC18 -injected plants was similar to that in the water- and buffertreated controls (Fig. 4). This result demonstrates that NOmediated disease resistance also requires the function of SA.

Results from previous work have shown that TMV infection increased the level of endogenous NOS activity and that treatment with exogenous NOS activated defense responses (Durner et al. 1998). Whether SA initiates an NO burst during SAR induction in tobacco is yet unknown. In our experiments, the fact that SAR induction was significantly attenuated when the tobacco plants were coinjected with SA and the NOS inhibitors or the NO scavenger (Fig. 3) implies that not only are NOS-like enzymes activated by SA, but also, the activated NOS-like enzymes catalyze the generation of NO which, in turn, is required for SAR induction. NOS inhibitors have also been found to suppress the NO burst and, therefore, inhibit hypersensitive cell death in Arabidopsis cells challenged with avirulent bacteria or in tobacco cells treated with cryptogein

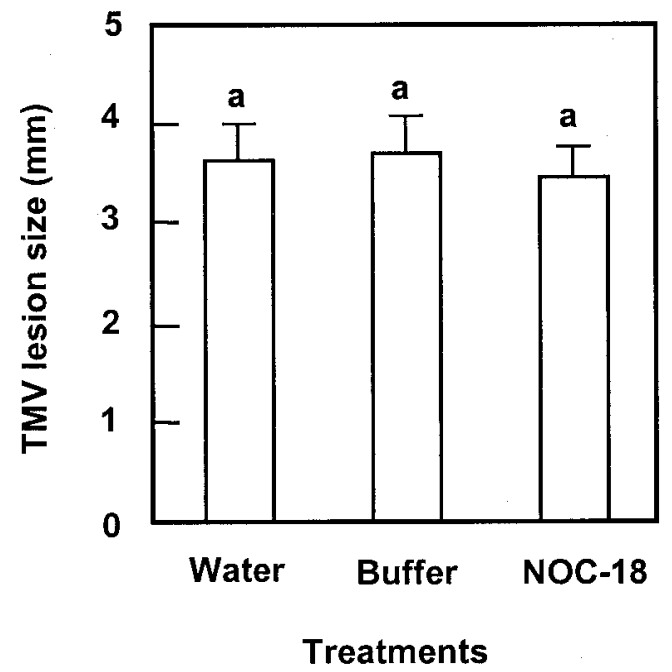

Fig. 4. Nitric oxide-mediated disease resistance requires salicylic acid in tobacco. Four-week-old $N a h G$ transgenic tobacco (cv. Xanthi nc) plants were injected with NOC-18 (1.0 mM) in $10 \mathrm{mM}$ potassium phosphate buffer ( $\mathrm{pH} 7.4$ ), as well as the buffer or water, at four locations on a single leaf. The treated and upper nontreated leaves were challenged by inoculation with Tobacco mosaic virus 5 days after treatment. Lesion size was measured 7 days after inoculation. The data presented are the means \pm standard deviations from three independent experiments. The bars with the same letter are not significantly different at $P \leq 0.05$. 
(Clarke et al. 2000; Delledonne et al. 1998; Foissner et al. 2000). Thus, activation of NOS-like enzymes and the generation of NO via NOS-mediated mechanisms are important early events in the signaling pathways leading to the activation of various defense responses.

In $N a h G$ transgenic plants, treatment with NO-releasing compounds failed to induce resistance (Fig. 4). Taken together with results of previous work (Durner et al. 1998) on the induction of $P R-1$ gene expression in tobacco by NO and the increase in endogenous SA levels following treatment with NOS, cofactors, and substrates, we conclude NO-mediated disease resistance requires the action of SA and NO may function upstream of SA in the SAR signaling pathway.

Notably, however, treatment with NOS inhibitors and an NO scavenger attenuated, but did not abolish, the SAR response induced by SA (Fig. 3). It was previously reported that L-NMMA $(150 \mu \mathrm{M})$ completely inhibited the induction of PR1 protein accumulation when coinjected with NOS, cofactors, and substrates into tobacco leaves (Durner et al. 1998). Likewise, PTIO (400 mM) inhibited the NO burst induced by fungal elicitor in suspension-cultured tobacco cells (Foissner et al. 2000). We used relatively higher concentrations of LNMMA $(300 \mu \mathrm{M})$ and PTIO $(1.0 \mathrm{mM})$ in our experiments than those used by Durner and associates (1998) and Foissner and associates (2000). Our results indicate that the attenuation of SA-induced SAR may be a consequence of the lack of NO, but SA can still activate a partial SAR response in the absence of NO. Together, these findings suggest that NO is required for the full function of SA, but NO is fully dependent on the function of SA in the SAR signaling pathway. These results are consistent with the model proposed by Durner and Klessig (1999) for the relationship between NO, SA, and oxidative burst. These authors proposed that NO and oxidative burst induced SA synthesis, while elevated SA, in turn, leads to further enhancement of $\mathrm{NO}$ and oxidative burst. It is also possible that the apparent attenuation of the SA-induced SAR response is due to the relatively long interval ( 5 days) that we used between pretreatment with mixtures of SA and NOS inhibitors or the NO scavenger and TMV inoculation. Future experiments are needed to examine the course of metabolism in plants of the NOS inhibitors and PTIO and to further assess the effect of these treatments on SA itself or its ability to induce the SAR response.

Pretreatment of lower tobacco leaves with NO-releasing compounds led to reduced lesion size in upper leaves (Fig. 1), suggesting that signal(s) required for the development of SAR in the upper leaves might be produced in the lower leaves pretreated with NO-releasing compounds. The systemic mobile signals in SAR have been studied extensively for many years, but the nature of the signals is still unknown. SA is an important signal for SAR development and is required for the activation of defense responses in noninduced systemic tissues; however, results from grafting experiments between $N a h G$ and wild-type tobacco plants have suggested that SA is not the long-distance mobile signal in SAR (Pallas et al. 1996; Vernooij et al. 1994). NO in the form of GSNO as the longdistance signal in plant disease resistance has not been established. Further studies that employ grafting of NahG plant rootstocks and wild-type plant scions, and vice versa, would address whether SA and NO, or NO alone, is responsible for NO-mediated SAR in tobacco.

\section{ACKNOWLEDGMENTS}

This work was supported in part by The McKnight Foundation. F. Song thanks the Syngenta (Novartis) Crop Protection, Inc. for financial support for his visit to R. M. Goodman's laboratory. We thank T. Gaffney for seeds of NahG transgenic tobacco.

\section{LITERATURE CITED}

Barroso, J. B., Corpas, F. J., Carreras, A., Sandalio, L. M., Valderrama, R., Palma, J. M., Lupianez, J. A., and del Rio, L. A. 1999. Localization of nitric oxide synthase in plant peroxisomes. J. Biol. Chem. 274: 36729-36733.

Beligni, M. V., and Lamattina, L. 1999a. Nitric oxide counteracts cytotoxic processes mediated by reactive oxygen species in plant tissues. Planta 208:337-344.

Beligni, M. V. and Lamattina, L. 1999b. Nitric oxide protects against cellular damage produced by methylviologen herbicides in potato plants. Nitric Oxide 3:199-208.

Beligni, M. V. and Lamattina, L. 2000. Nitric oxide stimulates seed germination and de-etiolation and inhibits hypocotyl elongation: Three light-inducible responses in plants. Planta 210:215-221.

Bolwell, G. P. 1999. Role of active oxygen species and NO in plant defence responses. Curr. Opin. Plant Biol. 2:287-294.

Clark, D., Durner, J., Navarre, D. A., and Klessig, D. F. 2000. Nitric oxide inhibition of tobacco catalase and ascorbate peroxidase. Mol. Plant-Microbe Interact. 13:1380-1384.

Clarke, A., Desikan, R., Hurst, R. D., Hancock, J. T., and Neill, S. J. 2000. NO way back: Nitric oxide and programmed cell death in Arabidopsis thaliana suspension cultures. Plant J. 24:667-677.

Cueto, M., Hernández-Perea, O., Martín, R., Bentura, M. L., Rodrigo, J., Lamas, S., and Golvano, M. P. 1996. Presence of nitric oxide synthase activity in roots and nodules of Lupinus albus. FEBS (Fed. Eur. Biochem. Soc.) Lett. 398:159-164.

Delledonne, M., Xia, Y., Dixon, R. A., and Lamb, C. 1998. Nitric oxide functions as a signal in plant disease resistance. Nature 394:585-588.

Dong, X. 1998. SA, JA, ethylene, and disease resistance in plants. Curr. Opin. Plant Biol. 1:316-323.

Dong, X. 2001. Genetic dissection of systemic acquired resistance. Curr. Opin. Plant Biol. 4:309-314.

Durner, J., and Klessig, D. F. 1999. Nitric oxide as a signal in plants. Curr. Opin. Plant Biol. 2:369-374.

Durner, J., Wendehenne, D., and Klessig, D. F. 1998. Defense gene induction in tobacco by nitric oxide, cyclic GMP and cyclic ADP ribose. Proc. Natl. Acad. Sci. U.S.A. 95:10328-10333.

Foissner, I., Wendehenne, D., Langebartels, C., and Durner, J. 2000. In vivo imaging of an elicitor-induced nitric oxide burst in tobacco. Plant J. 23:817-824.

Gaffney, T., Friedrich, L., Vernooij, B., Negrotto, D., Nye, G., Uknes, S., Ward, E., Kessmann, H., and Ryals, J. 1993. Requirement for salicylic acid for the induction of systemic acquired resistance. Science 261: 754-756.

Gouvea, C. M. C. P., Souza, J. F., Magalhaes, A. C. N., and Martins, I. S. 1997. NO-releasing substances that induce growth elongation in maize root segments. Plant Growth Reg. 21:183-187.

Hausladen, A., and Stamler, J. S. 1998. Nitric oxide in plant immunity. Proc. Natl. Acad. Sci. U.S.A. 95:10345-10347.

Huang, J.-S., and Knopp, J. A. 1998. Involvement of nitric oxide in Ralstonia solanacearum-induced hypersensitive reaction in tobacco. Pages 218-224 in: Bacterial Wilt Disease: Molecular and Ecological Aspects. P. Prior, J. Elphinstone, and C. Allen, eds. INRA and Springer Editions, Berlin.

Klepper, L. 1991. NOx evolution by soybean leaves treated with salicylic acid and selected derivatives. Pest. Biochem. Physiol. 39:43-48.

Klessig, D. F., Durner, J., Noad, R., Navarre, D. A., Wendehenne, D., Kumar, D., Zhou, J. M., Shah, J., Zhang, S., Kachroo, P., Trifa, Y., Pontier, D., Lam, E., and Silva, H. 2000. Nitric oxide and salicylic acid signaling in plant defense. Proc. Natl. Acad. Sci. U.S.A. 97:8849-8855.

Kumar, D., and Klessig, D. F. 2000. Differential induction of tobacco MAP kinases by the defense signals nitric oxide, salicylic acid, ethylene, and jasmonic acid. Mol. Plant-Microbe Interact. 13:347-351.

Kurosaki, F., Arisawa, M., Shudo, K., Okamoto, T., and Isogai, Y. 2000. Nitric oxide form of a pyridylphenylurea is a potent inducer of shoot 
formation in plant tissue cultures. Anal. Biochem. 278:81-83.

Leshem, Y. Y., and Pinchasov, Y. 2000. Non-invasive photoacoustic spectroscopic determination of relative endogenous nitric oxide and ethylene content stoichiometry during the ripening of strawberries Fragaria anannasa (Duch.) and avocados Persea americana (Mill.). J. Exp. Bot. 51:1471-1473.

Leshem, Y. Y., Wills, R. B. H., and Veng-Va Ku, V. 1998. Evidence for the function of the free radical gas-nitric oxide (NO) as an endogenous maturation and senescence regulating factor in higher plants. Plant Physiol. Biochem. 36:825-833.

Mackerness, S. A. H., John, C. F., Jordan, B., and Thomas, B. 2001. Early signaling components in ultraviolet-B responses: Distinct roles for different reactive oxygen species and nitric oxide. FEBS (Fed. Eur. Biochem. Soc.) Lett. 489:237-242.

Navarre, D. A., Wendehenne, D., Durner, J., Noad, R., and Klessig, D. F. 2000. Nitric oxide modulates the activity of tobacco aconitase. Plant Physiol. 122:573-582.

Ninnemann, H., and Maier, J. 1996. Indications for the occurrence of nitric oxide synthase in fungi and plants and the involvement in photoconidiation of Neurospora crassa. Photochem. Photobiol. 64: 393-398.

Noritake, T., Kawakita, K., and Doke, N. 1996. Nitric oxide induces phytoalexin accumulation in potato tuber tissues. Plant Cell Physiol. 37:113-116.

Pallas, J. A., Paiva, N. L., Lamb, C., and Dixon, R. A. 1996. Tobacco plants epigenetically suppressed in phenylalanine ammonia-lyase expression do not develop systemic acquired resistance in response to infection by tobacco mosaic virus. Plant J. 10:281-293.

Pedroso, M. C., Magalhaes, J. R., and Durzan, D. 2000. A nitric oxide burst precedes apoptosis in angiosperm and gymnosperm callus cells and foliar tissues. J. Exp. Bot. 51:1027-1036.

Ribeiro, E. A., Cunha, F. Q., Tamashiro, W. M. S. C., and Martins, I. S. 1999. Growth phase-dependent subcellular localisation of nitric oxide synthase in maize cells. FEBS (Fed. Eur. Biochem. Soc.) Lett. 445: 283-286.

Ross, A. F. 1961. Systemic acquired resistance induced by localized virus infections in plants. Virology 14:340-358.

Sen, S. and Cheema, I. R. 1995. Nitric oxide synthase and calmodulin immunoreactivity in plant embryonic tissue. Biochem. Arch. 11:221227.

Vernooij, B., Friedrich, L., Morse, A., Reist, R., Kolditz-Jawhar, R., Ward, E., Uknes, S., Kessmann, H., and Ryals, J. 1994. Salicylic acid is not the translocated signal responsible for inducing systemic acquired resistance but is required in signal transduction. Plant Cell 6:959-965.

Ward, E. R., Uknes, S. J., Williams, S. C., Dincher, S. S., Wiederhold, D. L., Alexander, D. C., Ahl-Goy, P., Metraux, J.-P., and Ryals, J. A. 1991. Coordinate gene activity in response to agents that induce systemic acquired resistance. Plant Cell 3:1085-1094

Wendehenne, D., Pugin, A., Klessig, D. F., and Durner, J. 2001. Nitric oxide: Comparative synthesis and signaling in animal and plant cells. Trends Plant Sci. 6:177-183.

Wink, D. A., and Mitchell, J. B. 1998. Chemical biology of nitric oxide: Insight into regulatory, cytotoxic, and cytoprotective mechanisms of nitric oxide. Free Radic. Biol. Med. 25:434-456.

Yamasaki, H., and Sakihama, Y. 2000. Simultaneous production of nitric oxide and peroxynitrite by plant nitrate reductase: In vitro evidence for the NR-dependent formation of active nitrogen species. FEBS (Fed. Eur. Biochem. Soc.) Lett. 468:89-92. 